\title{
IgM-producing Chronic Lymphocytic Leukemia Cells Undergo Immunoglobulin Isotype-switching without Acquiring Somatic Mutations
}

\author{
Dimitar G. Efremov, ${ }^{\star \ddagger}$ Martin Ivanovski, ${ }^{\star \ddagger}$ Facundo D. Batista, ${ }^{\star}$ Gabriele Pozzato, ${ }^{\S}$ and Oscar R. Burrone ${ }^{\star}$ \\ *International Centre for Genetic Engineering and Biotechnology, Area Science Park, Trieste, Italy; ${ }^{\ddagger}$ Hematology Clinic, Faculty of \\ Medicine, Skopje, Macedonia, and ${ }^{\S}$ Ospedale di Cattinara, Strada di Fiume, Trieste, Italy
}

\begin{abstract}
The malignant $\mathrm{B}$ cells in chronic lymphocytic leukemia (CLL) typically express low-density membrane IgM or IgM/ IgD. In vitro experiments have shown that the CLL cells can be induced to differentiate into cells that secrete immunoglobulin (Ig) and can occasionally undergo heavy $(\mathrm{H})$ chain class switching. We now show that the CLL cells also undergo isotype-switching in vivo, since $\gamma$ and/or $\alpha \mathrm{H}$ chain transcripts with identical FW3/CDR3/FW4 regions as the $\mu$ CLL transcripts were detected in all of the 13 investigated patients with $\operatorname{IgM}^{+}$CLL. In most cases switching had occurred to $\alpha 1$ and $\gamma 3$, but CLL transcripts corresponding to the other $\gamma$ chain isotypes were also detected. In one case both the productively and nonproductively rearranged allele were found to undergo $\mathrm{H}$ chain class switching. CLL $\gamma$ transcripts were also present in surface $\mathrm{IgG}^{+}$sorted $\mathrm{B}$ cells, demonstrating that a small subset of the CLL cells express membrane IgG. In addition, transcripts encoding secretory $\gamma 2$ and $\gamma 3 \mathrm{H}$ chains were detected in two cases, which suggests that some serum IgG could be produced by the leukemic clone. Analysis of sorted PBL showed that isotypeswitching occurs in CLL cells that express the CD5 antigen. Finally, nucleotide sequence analysis showed that the $\mu, \alpha$, and $\gamma$ CLL transcripts are identical, demonstrating that the CLL cells do not accumulate somatic mutations in their variable region genes after the $H$ chain class switching. These data provide in vivo evidence that isotype-switching is a frequent phenomenon in CLL, and indicate that a subset of the CLL lymphocytes progress to later stages of B cell differentiation. (J. Clin. Invest. 98:290-298.) Key words: B cell leukemia • immunoglobulin variable region • heavy chain • class switching • CD5 antigen
\end{abstract}

\section{Introduction}

B cell chronic lymphocytic leukemia results from an accumulation of monoclonal $\mathrm{CD}^{+} \mathrm{B}$ lymphocytes that express low-density membrane $\mathrm{Ig}$, most often of the $\operatorname{IgM}$ or $\operatorname{IgM} / \operatorname{IgD}$ isotype $(1,2)$. In a small proportion of cases the chronic lymphocytic

Address correspondence to Dr. Oscar R. Burrone, ICGEB, Area Science Park, Padriciano 99, 34012 Trieste, Italy. Phone: 40-3757314; FAX: 40-226555.

Received for publication 27 December 1995 and accepted in revised form 30 April 1996.

J. Clin. Invest.

(c) The American Society for Clinical Investigation, Inc.

0021-9738/96/07/0290/09 \$2.00

Volume 98, Number 2, July 1996, 290-298 leukemia (CLL) $)^{1}$ cells express IgG or IgA on their surface, indicating that more differentiated CLL variants also exist $(3,4)$. In vitro experiments further suggest that the CLL cells can progress to the final stages of B cell maturation. In particular, incubation of CLL cells with polyclonal B cell activators or T cells can induce them to differentiate into plasmacytoid cells that produce secretory IgM (5-7). Mitogen-induced class-switching from cell-surface IgM to secretory $\operatorname{IgG}$ or $\operatorname{IgE}$ has also been reported $(8,9)$.

Less well documented is the capacity of the CLL cells to terminally differentiate in vivo. In one study a small proportion of plasmacytoid cells expressed the same Ig idiotype as the CLL lymphocytes, indicating that these two B cell populations were clonally related (10). The presence of low levels of circulating monoclonal Igs in the majority of CLL patients also suggests that some of the CLL lymphocytes differentiate in vivo into Ig secreting cells (11-15). Some of these studies have shown that the monoclonal serum Ig and the surface Ig of the CLL cells frequently express the same light chain class and idiotype $(14,15)$, but this has not been confirmed in other reports (16). Furthermore, in most cases the monoclonal serum Ig differs from the CLL Ig in $\mathrm{H}$ chain isotype, indicating that either these Igs are not related or that a subset of the CLL cells has undergone isotype-switching $(15,16)$.

Using an isotype-specific Ig gene fingerprinting assay, we now show that isotype-switched CLL cells exist in the peripheral blood of all investigated patients with $\operatorname{IgM}^{+}$CLL. A subset of these cells express $\gamma$ transcripts that can encode secretory $\mathrm{H}$ chains, indicating that some of the monoclonal serum Igs could be produced by the leukemic clones.

\section{Methods}

Samples. Peripheral blood mononuclear cells (PBMC) from 13 patients with surface $\operatorname{IgM}^{+}$B-CLL were isolated from fresh whole blood by density gradient centrifugation with Lymphoprep (Nycomed Pharma, Oslo, Norway). The cells were washed with PBS and in some cases aliquots were taken for magnetic bead separation while the remaining cells were used directly for RNA extraction. Positive selection of $\mathrm{CD}^{+}$or $\mathrm{CD} 38^{+}$cells was done by incubating $1-5 \times 10^{7}$ cells with a monoclonal mouse anti-human CD5 Ab (Biosource, Camarillo, CA) or a monoclonal mouse anti-human CD38 Ab (Monosan, Uden, The Netherlands), respectively. After washing, the cells were incubated with magnetic beads coated with sheep anti-mouse IgG (Dynabeads M-450; Dynal, Oslo, Norway) at a 3:1 ratio, washed five times to remove any non-specifically bound cells and collected with a Dynal MPC magnetic stand. Positive selection of surface $\mathrm{IgG}^{+}$or surface $\mathrm{IgA}^{+}$cells was done in the same manner as above, except that Rabbit anti-human IgG or Rabbit anti-human IgA immunoglobulins (both from DAKO, Glostrup, Denmark) were used with magnetic beads coated with sheep anti-rabbit IgG (Dynabeads M-280, Dynal).

1. Abbreviations used in this paper: CLL, chronic lymphocytic leukemia; $\mathrm{CH}$, constant heavy; H-chain, heavy-chain; PBL, peripheral blood lymphocytes; RT, reverse transcription. 
The number of surface $\operatorname{IgM}^{+}, \operatorname{IgG}^{+}$and $\operatorname{IgA}^{+}$cells was determined by flow-cytometry (FACStar ${ }^{\circledR}$ Plus, Becton Dickinson, Mountain View, CA) and immunofluorescence analysis with fluorescein-conjugated goat anti-human $\operatorname{IgM}$, anti-human $\operatorname{IgG}$ and anti-human $\operatorname{IgA~F}\left(\mathrm{ab}^{\prime}\right)_{2}$ fragments (Jackson Immunoresearch Laboratories, West Grove, PA).

Isotype-specific Ig gene fingerprinting analysis of $H$ chain transcripts. Total cellular RNA was isolated from PBMC by the procedure of Chomczynski and Sacchi (17). $1 \mu \mathrm{g}$ of RNA was reverse transcribed (RT) using oligo-dT and the GeneAmp RNA/PCR kit (Perkin Elmer Cetus, Norwalk, CT), following the procedure recommended by the manufacturer. The cDNA from each patient was amplified in six separate PCR reactions using the consensus $\mathrm{V}_{\mathrm{H}}$-specific oligonucleotide primer hV2 (5' CTGAGGACACGGCCGTGTATTACTG $3^{\prime}$, codons 84 to 92 in FW3) and one of the six isotype-specific primers from the $\mathrm{C}_{\mathrm{H}} 1$, hinge or $\mathrm{C}_{\mathrm{H}} 2$ exons of the constant region genes (hM 5' GTCCTGTGCGAGGCAGCCAA 3', codons 140 to 146; hA 5' AGTCGGGGGTGGCAGCATG 3', codons 250 to 254; hG1 5' CATGTGTGAGTTTTGTCACAAGA $3^{\prime}$, codons 229 to 239; hG2 5' GGTGGGCACTCGACACAACA $3^{\prime}$, codons 232 to 241; hG3 $5^{\prime}$ AGTTGTGTCACCAAGTGGGGT 3', codons 229 to 236; and hG4 5' TGATGGGCATGGGGGACCAT 3', codons 229 to 241; codon numbers according to ref 18) (see scheme in Fig. 1). The PCRs were done with $50 \mathrm{pmol}$ of each primer using 35 cycles of denaturation at $95^{\circ} \mathrm{C}$ for 1 minute, annealing at $64^{\circ} \mathrm{C}$ for $1 \mathrm{~min}$ and synthesis at $72^{\circ} \mathrm{C}$ for 1 min and $30 \mathrm{~s}$. 20- $\mu \mathrm{l}$ aliquots of each PCR reaction were next labeled by primer extension with the corresponding internal ${ }^{32} \mathrm{P}$-labeled oligonucleotides hMi (5' GGAAAAGGGTTGGGGCGGAT 3'), hAi (5' CGAAGACCTTGGGGCTGGTC $3^{\prime}$ ) and hGc (5' GGAAGACCGATGGGCCCTTG $3^{\prime}$ ), all of which are located 8 nucleotides downstream from the beginning of the $\mathrm{C}_{\mathrm{H}} 1$ exons. The reaction mixtures (20 $\mu \mathrm{l}$ of the PCR sample, $10 \mathrm{pM}$ of ${ }^{32} \mathrm{P}$ end-labeled primer, 200 $\mu \mathrm{M}$ dNTP, $0.5 \mu \mathrm{l}$ of GeneAmp 10xPCR Buffer and 1.25 U of Taq polymerase [both from Perkin Elmer Cetus], in a final volume of 25 $\mu \mathrm{l})$ were subjected to denaturation at $95^{\circ} \mathrm{C}$ for $8 \mathrm{~min}$, annealing at $64^{\circ} \mathrm{C}$ for $1 \mathrm{~min}$, and extension at $72^{\circ} \mathrm{C}$ for $15 \mathrm{~min} .2 \mu \mathrm{l}$ of each reaction were analyzed on denaturing $6 \mathrm{M}$ urea $6 \%$ polyacrylamide sequencing gels, with sequencing reactions used as size markers (19). Primer extensions with oligonucleotides specific for the CDR3 regions of the leukemic clones were done as described for the $\mathrm{hMi}, \mathrm{hAi}$, and $\mathrm{hGc}$ primers, except that the annealing temperatures were adjusted according to the melting temperature of each CDR3-specific oligonucleotide.

$R T / P C R$ analysis of secretory $\gamma$ chain transcripts. To investigate the relative amounts of secretory $\gamma 1, \gamma 2, \gamma 3$ and $\gamma 4 \mathrm{H}$ chain transcripts in normal and CLL cells, cDNA obtained by reverse transcription of PBMC mRNA was amplified with the FW3 primer hV2 and a consensus oligonucleotide from the $3^{\prime}$ untranslated regions of the secretory $\gamma$ transcripts (hGs $5^{\prime}$ GGGGTACGTGCCAAGCAT 3 ') (see Fig. 5). To analyze only CLL transcripts, the cDNA was separately amplified with a CDR3-specific oligonucleotide instead of the hV2 primer. Aliquots of each PCR were ${ }^{32} \mathrm{P}$-labeled by primer extension with each of the four isotype-specific $\mathrm{C} \gamma$ primers (hG1, hG2, hG3, and hG4) and analyzed by denaturing-PAGE as described above.

Cloning and sequencing of isotype-switched CLL $H$ chain transcripts. PCR fragments amplified with the consensus $\mathrm{V}_{\mathrm{H}}$ specific primer $\mathrm{hV} 2$ and the isotype-specific primers $\mathrm{hA}, \mathrm{hG} 1, \mathrm{hG} 2, \mathrm{hG} 3$, and hG4 were purified by electroelution from $1.2 \%$ agarose gels. The recovered DNA fragments were ligated in the SmaI site of pUC18 (Pharmacia LKB, Uppsala, Sw) and were used to transform E. coli strain DH5 $\alpha$. Clones containing isotype-switched CLL sequences were identified by colony hybridization with CDR3-specific oligonucleotides, and double-stranded DNA template was sequenced using the T7 Sequencing Kit (Pharmacia LKB).

Table I. Isotype-switched CLL H-chain Transcripts Detected in 13 IgM+ CLL Patients

\begin{tabular}{|c|c|c|c|c|c|c|c|c|c|}
\hline \multirow{2}{*}{$\begin{array}{l}\text { CLL } \\
\text { patient }\end{array}$} & \multirow[b]{2}{*}{$\mathrm{V}_{\mathrm{H}}$ gene } & \multirow[b]{2}{*}{$D_{\mathrm{H}}$ gene } & \multirow[b]{2}{*}{$\mathrm{J}_{\mathrm{H}}$ gene } & \multirow[b]{2}{*}{ Sampling } & \multicolumn{5}{|c|}{ Isotype-switched CLL H-chain transcripts* } \\
\hline & & & & & $\alpha$ & $\gamma 1$ & $\gamma 2$ & $\gamma 3$ & $\gamma 4$ \\
\hline \multirow[t]{2}{*}{ HA-1 } & $51 \mathrm{p} 1$ & DXP4 & $\mathrm{J}_{\mathrm{H}} 6 \mathrm{~b}$ & $1 \mathrm{st}$ & ++ & + & + & ++ & + \\
\hline & & & & 2nd & ++ & - & - & + & + \\
\hline \multirow[t]{3}{*}{ CL-P } & $\mathrm{V}_{\mathrm{H}} 4.21$ & D4 & $\mathrm{J}_{\mathrm{H}} 6 \mathrm{~b}$ & $1 \mathrm{st}$ & + & + & ++ & ++ & - \\
\hline & & & & $2 \mathrm{nd}$ & ++ & + & ++ & ++ & + \\
\hline & & & & $3 r d$ & + & + & +++ & ++ & n.a. \\
\hline \multirow[t]{4}{*}{ HA-5 } & $51 \mathrm{p} 1$ & DXP4 & $\mathrm{J}_{\mathrm{H}} 6 \mathrm{~b}$ & $1 \mathrm{st}$ & +++ & - & + & + & - \\
\hline & & & & $2 \mathrm{nd}$ & +++ & - & + & ++ & + \\
\hline & & & & $3 r d$ & +++ & + & + & ++ & + \\
\hline & & & & 4 th & ++ & + & + & ++ & n.a. \\
\hline HA-2 & $51 \mathrm{p} 1$ & DXP4 & $\mathrm{J}_{\mathrm{H}} 4 \mathrm{~b}$ & & + & - & - & ++ & + \\
\hline CL-J & DP-50 & D6-D3 & $\mathrm{J}_{\mathrm{H}} 5 \mathrm{~b}$ & & + & - & + & - & +++ \\
\hline HA-8 & DP-46 & DXP4 & $\mathrm{J}_{\mathrm{H}} 6 \mathrm{~b}$ & & + & + & ++ & + & - \\
\hline HA-11 & DP-47 & DXP1 & $\mathrm{J}_{\mathrm{H}} 4 \mathrm{~b}$ & & + & - & + & + & - \\
\hline HA-4 & DP-50 & DXP1 & $\mathrm{J}_{\mathrm{H}} 6 \mathrm{~b}$ & & ++ & +++ & +++ & ++ & - \\
\hline HA-6 & DP-47 & DN1 & $\mathrm{J}_{\mathrm{H}} 5 \mathrm{~b}$ & & +++ & + & - & ++ & - \\
\hline GP-1 & DP-8 & $\mathrm{D} 2$ & $\mathrm{~J}_{\mathrm{H}} 3 \mathrm{~b}$ & & - & + & + & + & - \\
\hline HA-7 & DP-50 & DN4 & $\mathrm{J}_{\mathrm{H}} 4 \mathrm{~b}$ & & ++ & + & ++ & ++ & - \\
\hline HA-RI & DP-50 & DLR1 & $\mathrm{J}_{\mathrm{H}} 6 \mathrm{~b}$ & & + & - & - & + & - \\
\hline HA-Idr.$^{\S}$ & $51 \mathrm{P} 1$ & DN2-DLR4 & $\mathrm{J}_{\mathrm{H}} 3 \mathrm{~b}$ & & + & + & ++ & ++ & - \\
\hline HA-Idr n.p. & DP-59 & DXP4 & $\mathrm{J}_{\mathrm{H}} 5 \mathrm{~b}$ & & + & + & ++ & ++ & - \\
\hline
\end{tabular}

*The amount of CLL transcripts vs normal B-cell transcripts was estimated by comparing the intensities of the bands from the isotype-specific Ig gene fingerprints done with the consensus $V_{\mathrm{H}}$ primer: "+++" indicates that the band corresponding to the isotype-switched CLL transcripts was unique in the fingerprint; "++" indicates that the band corresponding to the isotype-switched CLL transcripts was dominant in a background of normal B-cell transcripts; "+" was assigned when the CLL band was of the same or less intensity than the majority of bands corresponding to normal B-cells. Samples were considered positive only when the specificity of the band corresponding to the isotype-switched CLL transcripts was confirmed with CDR3specific oligonucleotides. n.a., not analyzed; ${ }^{8} p$, productive allele; $n . p .$, nonproductive allele. 


\section{Results}

Detection of clonally related isotype-switched CLL H-chain transcripts. The $\mathrm{V}_{\mathrm{H}}, \mathrm{D}_{\mathrm{H}}$, and $\mathrm{J}_{\mathrm{H}}$ gene segments expressed by the leukemic clones of the $13 \mathrm{IgM}^{+}$CLL patients were determined in a parallel study of $\mathrm{V}_{\mathrm{H}}$ gene usage in CLL (20). As shown in Table I, five patients had rearranged $\mathrm{V}_{\mathrm{H}} 1$ family genes (51p1 in four and DP-8 in one case), seven patients had rearranged $\mathrm{V}_{\mathrm{H}} 3$ family genes (DP-50 in four, DP-47 in two and DP-46 in one case), and one patient had rearranged the $\mathrm{V}_{\mathrm{H}} 4$ family gene $\mathrm{V}_{\mathrm{H}}$ 4.21. Except for the $\mathrm{V}_{\mathrm{H}}$ gene segments of CLJ and HA-RI which were $93.5 \%$ and $92.1 \%$ homologous to DP-50, respectively, all other $\mathrm{V}_{\mathrm{H}}$ sequences were $100 \%$ homologous to germline $V_{H}$ genes (21). Also, the sequences of the $\mathrm{D}_{\mathrm{H}}$ and $\mathrm{J}_{\mathrm{H}}$ gene segments were identical to the assigned germ-line counterparts.

To determine if a subset of the $\operatorname{IgM}^{+}$CLL cells in these patients undergoes isotype-switching, we used an isotype-specific Ig gene fingerprinting assay to compare the CDR3 lengths of the $\mu, \alpha, \gamma 1, \gamma 2, \gamma 3$, and $\gamma 4$ PBL mRNAs $(19,22,23)$. The assay was based on specific amplification of cDNAs belonging to a particular $\mathrm{H}$ chain isotype, followed by radioactive labeling of the PCR products by primer-extension with internal isotypespecific oligonucleotides. Since these oligonucleotides were located at an equal distance from the FW4 region, bands corresponding to a particular CDR3 region would be of the same length regardless of the isotype (Fig. 1).

The analysis of a normal control and four CLL patients is shown in Fig. 2. A polyclonal pattern can be seen in all isotypes of the normal control, whereas a unique band, corre-

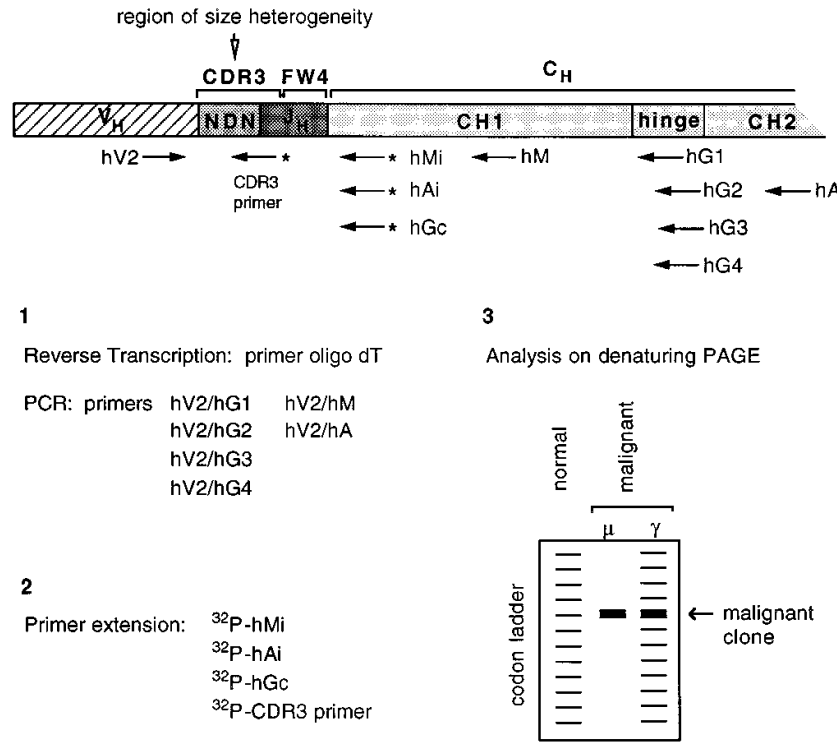

Figure 1. Schematic representation of isotype-specific Ig gene fingerprint analysis of $\mathrm{H}$ chain transcripts. Total cellular mRNA from peripheral blood lymphocytes (PBL) was reverse-transcribed and amplified in six separate $\mathrm{PCR}$ reactions with a consensus $\mathrm{V}_{\mathrm{H}}$-specific primer (hV2) and one of the six isotype-specific primers (hM, hA, hG1, hG2, hG3, and hG4) (step 1). The PCR fragments were radioactively labeled by primer-extension with the corresponding internal $\mathrm{C}_{\mathrm{H}}$ oligonucleotides hMi, hAi and hGc or with oligonucleotides specific for the CDR3 regions of the CLL clones (step 2). The radioactive fragments were separated on denaturing-PAGE to obtain codon ladders representing the size heterogeneity of the CDR3/FW4 regions (step 3). sponding to the CDR3/FW4 region of the leukemic clone, is present in the $\mu$ fingerprint of each CLL patient. In all cases with CLL, bands of the same size can be seen in some or all of the $\alpha$ and $\gamma$ fingerprints, indicating that some of the CLL cells have undergone isotype-switching. To confirm the specificity of these bands, the same PCR reactions were labeled by primer-extension with oligonucleotides complementary to the CDR3 regions of the leukemic clones. As shown in the lower panels of Fig. 2, single bands with the expected sizes for the CDR3 regions of the CLL clones were obtained in all cases.

Two bands were detected in the $\mu$ fingerprint of patient HA-Idr, which by nucleotide sequencing were found to represent productive and non-productive CLL $\mu$ transcripts. As judged by the intensity of the bands in the $\mu$ fingerprint, the productively and nonproductively rearranged allele were expressed at a similar level by the $\operatorname{IgM}^{+}$CLL cells (Fig. 3, top). This finding is interesting since it is generally believed that the expression of nonproductively rearranged Ig genes is substantially downregulated by posttranscriptional mechanisms (24, 25). To investigate if both alleles undergo isotype-switching, we performed primer extensions of the PCR amplified $\alpha$ and $\gamma$ transcripts with oligonucleotides specific for the CDR3 regions of the productive and non-productive allele. The primer-extension reactions were done with an equimolar mixture of the two oligonucleotides which had previously been labeled to the same specific activity. As shown in the bottom panel of Fig. 3, both the productively and nonproductively rearranged alleles underwent isotype-switching to $\alpha, \gamma 1, \gamma 2$, and $\gamma 3$. The ratio of productive vs non-productive CLL transcripts was similar in all isotypes except $\alpha$, where the productive allele was expressed at substantially higher levels.

An estimation of the relative amounts of isotype-switched CLL H-chain transcripts vs normal PBL transcripts is shown in Table I. In some cases, the isotype-switched CLL transcripts were the only transcripts that were detected, indicating that virtually all PBL expressing that isotype belonged to the leukemic clone (examples are the $\alpha$ transcripts in patients HA5 and HA6, and the $\gamma 1$ and $\gamma 2$ transcripts in patient HA4). In other cases, the CLL transcripts were present at lower levels than the transcripts expressed by the normal B cells. In three cases, repeated samplings over a two year interval showed a relatively constant ratio of CLL vs normal B cell transcripts, indicating that the isotype-switched CLL cells do not have the proliferative and/or survival capacity of their IgM-expressing progenitors (Table I and Figs. 2, 4, 5 and 6).

The isotype-switched transcripts are expressed as membrane Ig. To determine if the isotype-switched CLL H-chain transcripts are expressed as membrane Ig by a subset of the CLL cells, we analyzed the transcripts produced by surface $\mathrm{IgG}^{+}$and surface $\mathrm{IgA}^{+}$cells selected from PBL of patients CLP and HA5. As can be seen from the experiment shown in Fig. 4, the CLL bands in the $\gamma 1, \gamma 2$, and $\gamma 3$ fingerprints became clearly visible in the analysis of sorted cells, whereas they were hardly detectable in some isotypes of the total PBL samples (examples are $\gamma 3$ in CLP and $\gamma 1$ and $\gamma 2$ in HA5). This result clearly demonstrated that surface $\mathrm{IgG}^{+}$CLL cells are present in the peripheral blood of both patients. A weak CLL band was also detected in the $\alpha$ fingerprint of the $\operatorname{Ig} \mathrm{A}^{+}$cells from patient CLP, indicating that some membrane $\operatorname{IgA}$ reaches the surface of the CLL cells. However, no CLL $\alpha$ transcripts were detected in the surface $\operatorname{IgA}^{+}$B cells from patient HA5 (although such transcripts were present in the total PBL sample) suggesting that 

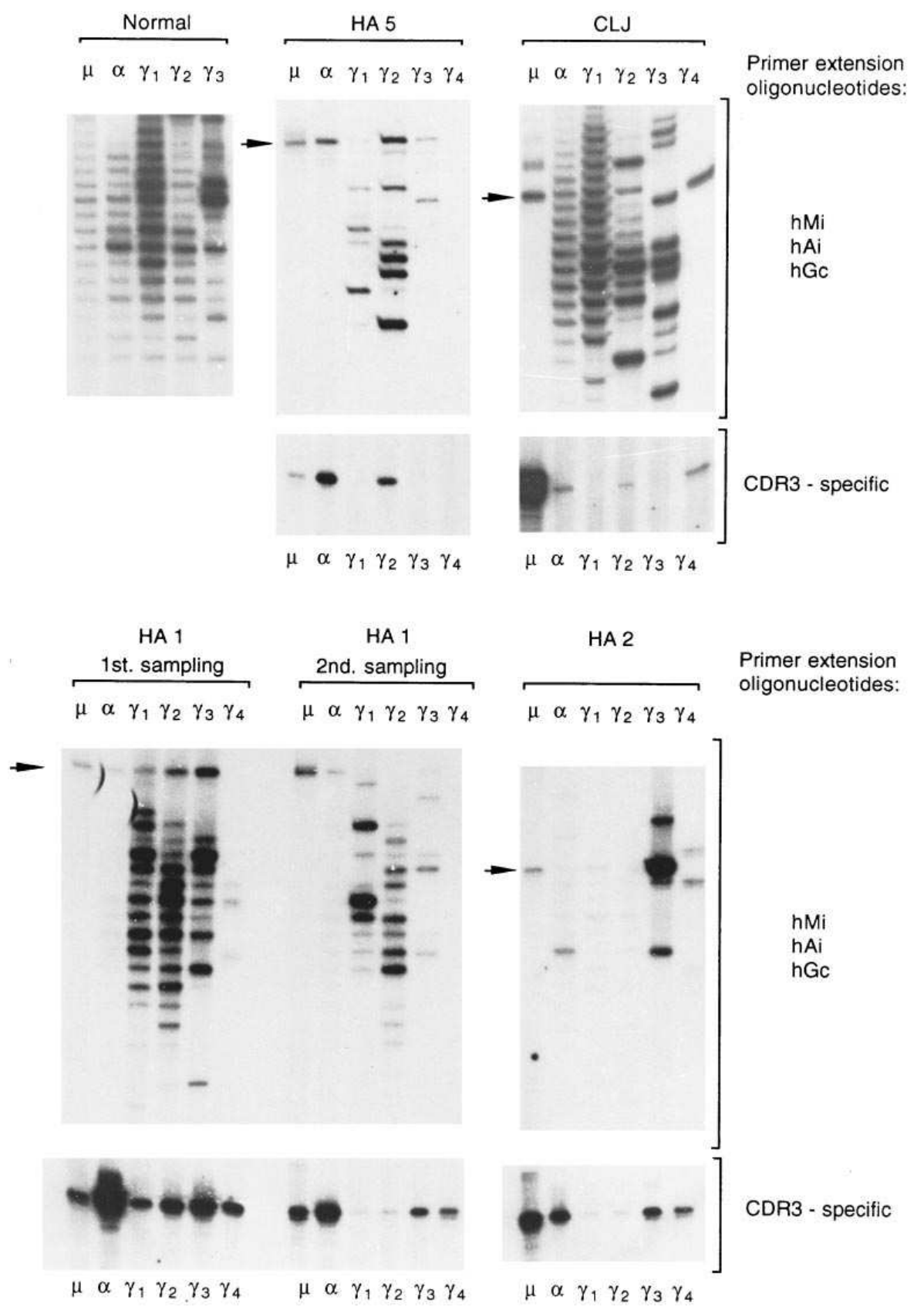

Figure 2. Isotype-specific Ig gene fingerprinting analysis of PBL mRNA from a normal individual and four CLL patients. The investigated $\mathrm{H}$ chain isotype is indicated above each lane with the symbols $\mu$, $\alpha, \gamma 1, \gamma 2, \gamma 3$, and $\gamma 4$. Primer extension reactions of the PCR fragments were done with the internal $\mathrm{C}_{\mathrm{H}}$ primers $\mathrm{hMi}, \mathrm{hAi}$, or hGc (shown in the top panels) or with the CDR3-specific primers (shown in the bottom panels). Arrows indicate the bands that correspond to the CLL clones. Sequencing reactions were used as size markers.

they were produced by more differentiated cells that lack or express lower levels of surface $\operatorname{IgA}$. This possibility could also explain the disappearance of some bands corresponding to normal B cells in the $\gamma 1$ - and $\gamma 3$-fingerprints of the sorted $\mathrm{IgG}^{+}$cells from patient CLP. It should be noted here, however, that the frequency of surface $\mathrm{IgG}^{+}$or surface $\mathrm{IgA}^{+}$CLL cells in these two patients was very low, since $<2 \%$ of their PBMC were positive by flow cytometry and immunofluorescence analysis.

The isotype-switched CLL cells produce secretory $\gamma H$ chain transcripts. To investigate whether the isotype-switched CLL cells have the capacity to produce serum IgG molecules, we selectively amplified the secretory $\gamma \mathrm{H}$ chain transcripts using a primer located immediately downstream of the stop codon from the $\mathrm{C}_{\mathrm{H}} 3$ exon (primer hGs in Fig. 5). This primer is complementary to a conserved sequence in the $3^{\prime}$ untranslated re- gions of the secretory $\gamma$ transcripts and therefore is expected to prime equally efficiently all four types of $\gamma$ cDNA, allowing estimation of their relative amounts after the PCR. Both normal and CLL transcripts were amplified when the FW3 primer hV2 was used with the common secretory $\gamma$ primer hGs, while only CLL transcripts were amplified when the hV2 oligonucleotide was substituted with a CDR3-specific primer. Aliquots of each PCR reaction were separately labeled by primer extension with the isotype-specific oligonucleotides from the hinge regions and analyzed by denaturing PAGE. The analysis of three different PBL samples from patient HA5 is shown in Fig. 5. A polyclonal pattern of secretory $\gamma$ transcripts belonging to the $\gamma 1, \gamma 2$, and $\gamma 3 \mathrm{H}$-chain isotypes was present in all samples amplified with the $\mathrm{hV} 2 / \mathrm{hGs}$ primer pair. No $\gamma 4$ transcripts were detected with this assay, which was expected considering 


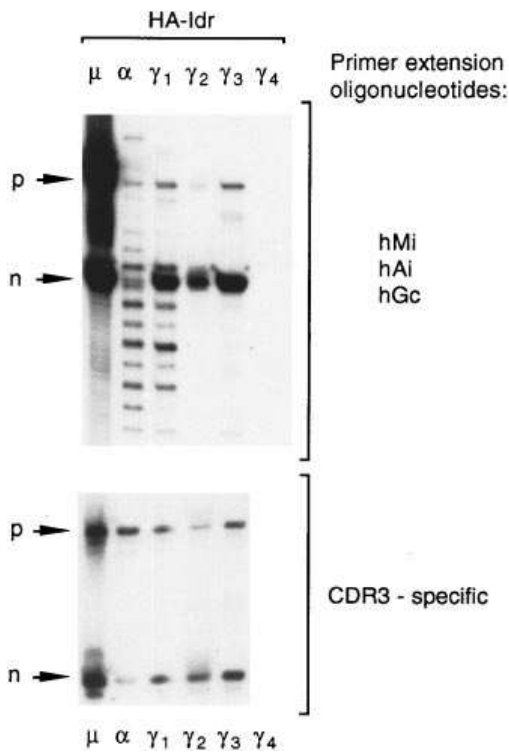

the low number of PBL that produce this isotype. Strong bands corresponding in size to the CLL clone were present in the $\gamma 2$ and $\gamma 3$ fingerprints. Their specificity was established by the analysis with the CDR3 specific primer, which confirmed that secretory CLL transcripts are present only in the $\gamma 2$ and $\gamma 3$ isotypes (Fig. 5, bottom) Secretory CLL H-chain transcripts belonging to the $\gamma 2$ and $\gamma 3$ isotypes were also detected in patient HA1 (data not shown).

Isotype-switched CLL transcripts are produced by $C D 5^{+}$ and $C D 38^{+} B$ cells. To investigate if the isotype-switched CLL cells express the CD5 antigen, we performed isotype specific Ig gene fingerprinting on $\mathrm{CD}^{+}$cells separated from PBL of two CLL patients (Fig. 6). Cells expressing the CD38 antigen were also analyzed to investigate if the isotype-switched CLL cells share some features with more differentiated B-cells. The CD38 marker is characteristically expressed at high levels on lymphoplasmacytoid and plasma cells $(26,27)$, and has also been detected on a proportion of CLL cells with atypical morphology (28).
As can be seen from the analysis of patient HA5, the polyclonal pattern of the unfractionated PBL in the $\gamma 1, \gamma 2$, and $\gamma 3$ isotypes almost completely disappeared after the cell-sorting, indicating that almost all of the $\mathrm{CD}^{+} \mathrm{B}$ cells in the peripheral blood of this patient belonged to the CLL clone (Fig. $6 a$ ). Similar results were obtained for patient CLP, except that in this case the number of normal $\mathrm{CD}^{+} \mathrm{B}$ cell clones was higher, especially in the $\gamma 1$ isotype (Fig. $6 b$ ). Interestingly, no CLL $\gamma 1$ transcripts were detected in the $\mathrm{CD}^{+}$sample, although such transcripts were present in the unfractionated PBL. On the other hand, analysis of the $\mathrm{CD} 38^{+} \mathrm{B}$ cell subset in this patient showed a predominance of $\gamma 1$ CLL transcripts, indicating that some of the isotype-switched CLL cells have differentiated into $\mathrm{CD}^{-} / \mathrm{CD} 38^{+}$cells.

The isotype-switched CLL H chain transcripts do not accumulate somatic mutations. In order to determine if the $\mathrm{V}_{\mathrm{H}}$ regions of the CLL cells acquire somatic mutations during $\mathrm{H}$-chain class switching, we analyzed isotype-switched transcripts from four CLL patients (Table II). PCR fragments spanning the FW3-CDR3-FW4-CH1 region of $\alpha, \gamma 1, \gamma 2$, and $\gamma 3$ transcripts were cloned, and positive clones were identified by colonyhybridization with CDR3-specific oligonucleotides. The $\gamma 1$ transcripts expressed by the $\mathrm{CD} 38^{+}$CLL cells were also analyzed to see if somatic mutations had accumulated in this CLL subset. Only three nucleotide substitutions were present in the FW3-CDR3-FW4 regions of the 48 sequenced clones. This low frequency of 1 mutation in $1638 \mathrm{nt}$ is the expected frequency for Taq polymerase errors (29). A similar mutation frequency of $1 / 1803 \mathrm{nt}$ was also observed in the $\mathrm{CH}$ region sequences (9 mutations in $16234 \mathrm{nt}$ ), demonstrating that the CLL cells do not undergo somatic mutation after $\mathrm{H}$ chain class switching.

The sequencing analysis also confirmed the specificity of our primers and allowed determination of the type of $\alpha$ transcripts produced by the CLL cells (the $\alpha 1$ and $\alpha 2$ transcripts could not be discriminated in the isotype-specific Ig gene fingerprinting assay because the PCR primers were homologous to both the $\mathrm{C} \alpha 1$ and $\mathrm{C} \alpha 2$ genes). Interestingly, only the $\alpha 1$ transcript was identified in the 12 sequenced $\alpha$ clones (obtained from two different patients), suggesting that the $\mathrm{C} \alpha 1$ gene is predominantly expressed by the CLL cells.

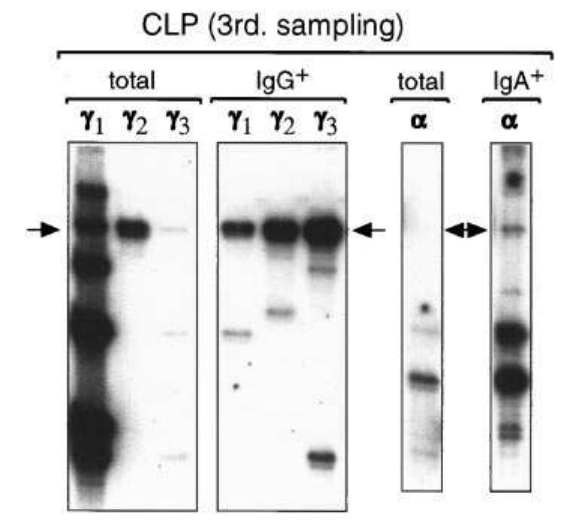

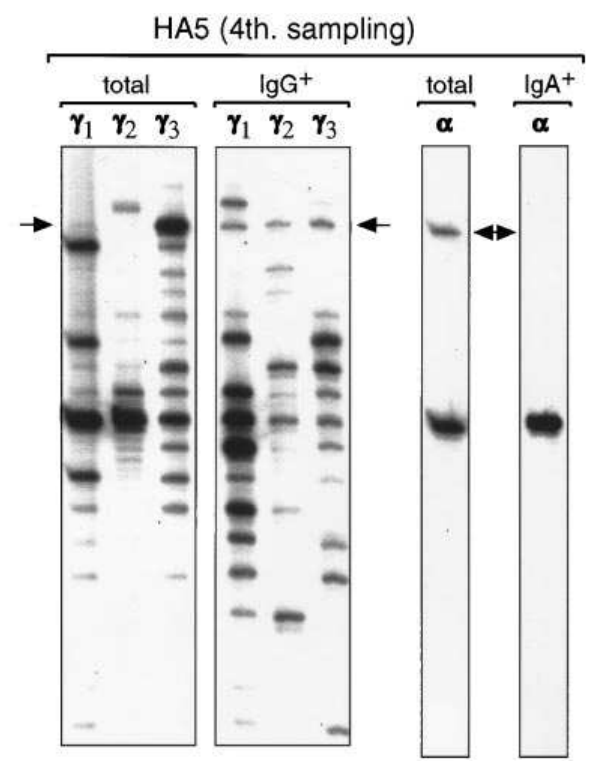

Figure 4. Fingerprinting analysis of sorted surface $\operatorname{IgG}^{+}$and surface $\operatorname{Ig} \mathrm{A}^{+}$cells. $\gamma 1, \gamma 2$, $\gamma 3$ and $\alpha$ transcripts were analyzed in total and sorted B cell populations from patients CLP and HA5. Arrows indicate the position of the CLL transcripts. 


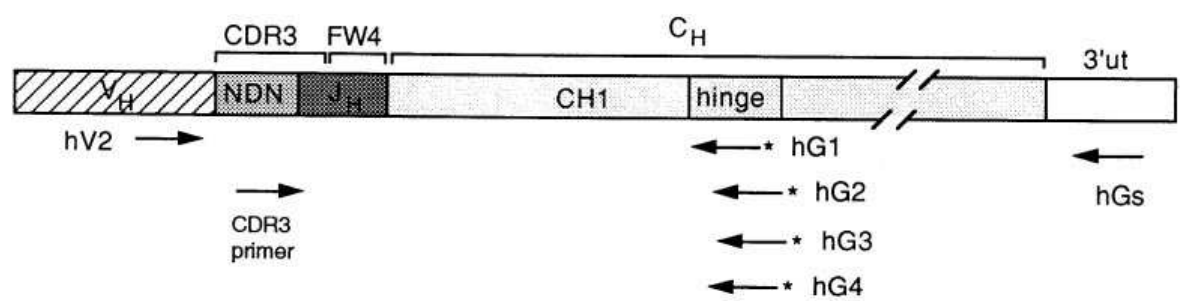

Figure 5. Analysis of secretory $\gamma$ transcripts expressed by PBL from CLL patient HA5. Three samples were collected at different intervals over a two year period. Each sample was amplified with the common secretory $\gamma$ primer (hGs) and the consensus $\mathrm{V}_{\mathrm{H}^{-}}$-specific primer (hV2) to detect the secretory $\gamma$ transcripts produced by both normal and CLL B-cells (top panel of autoradiogram). Only CLL transcripts were amplified when the hGs primer was used together with an oligonucleotide specific for the CDR3 region of the CLL clone (bottom panel of autoradiogram). Aliquots of each PCR were ${ }^{32} \mathrm{P}$-labeled by primer extension with each of the four isotype specific $\mathrm{C} \gamma$ primers (hG1, hG2, hG3 and hG4) and analyzed by denaturingPAGE.

\section{Discussion}

Recent molecular studies have confirmed the existence of potentially more differentiated CLL variants which have undergone $\mathrm{H}$ chain class switching and express membrane $\mathrm{IgG}$ or membrane $\operatorname{IgA}(4,30,31)$. In the present report, we show that isotype-switching is a common phenomenon in CLL, since isotype-switched CLL H-chain transcripts were detected in all of our $\operatorname{IgM}^{+}$CLL patients. In some cases, especially those with more pronounced hypogammaglobulinemia, the CLL bands were the only bands visible, indicating that in these patients the isotype-switched CLL cells were predominant among the peripheral blood B lymphocytes of that particular isotype. This is most likely to reflect the progressive dilution of normal B cells rather than a high proliferative and/or survival capacity of the isotype-switched CLL cells, since a relatively constant ratio of isotype-switched CLL vs normal B cell $\mathrm{H}$ chain transcripts was observed in the three patients that were followed over a two year period.

Table II. Nucleotide Sequence Analysis of Isotype-switched CLL H-chain Transcripts

\begin{tabular}{lcccc}
\hline Patient & $\begin{array}{c}\text { H-chain } \\
\text { isotype }\end{array}$ & $\begin{array}{c}\text { No. of } \\
\text { sequenced } \\
\text { clones }\end{array}$ & $\begin{array}{c}\text { No. of mutations in } \\
\text { FW3/CDR3/FW4 } \\
\text { regions }\end{array}$ & $\begin{array}{c}\text { No. of mutations } \\
\text { in } \text { C }_{\mathrm{H}} \text { regions }\end{array}$ \\
\hline HA1 & $\alpha 1$ & 6 & 2 & 1 \\
& $\gamma 3$ & 4 & None & None \\
HA2 & $\gamma 3$ & 6 & None & 2 \\
HA5 & $\alpha 1$ & 6 & None & 1 \\
& $\gamma 3$ & 6 & 1 & None \\
CLP & $\gamma 1\left(\mathrm{CD} 38^{+}\right)$ & 8 & None & 3 \\
& $\gamma 2$ & 6 & None & None \\
& $\gamma 3$ & 6 & None & 2 \\
\hline
\end{tabular}

Except for $\alpha 2$, isotype-switched CLL transcripts belonging to all investigated $\mathrm{H}$-chain classes were detected. The CLL cells most frequently produced $\alpha 1$ and $\gamma 3$ transcripts, which appeared as prominent bands in most fingerprints. Transcripts belonging to the $\gamma 1$ isotype were less frequently detected, which could be due to a high number of residual normal IgG1producing B-lymphocytes in the peripheral blood of these patients. Preferential expression of the $\mathrm{C} \gamma 3, \mathrm{C} \gamma 1$, and $\mathrm{C} \alpha 1$ genes was also observed in a study that examined the expression of germ-line transcripts by in vitro stimulated CLL cells (32). The absence of germ-line $\gamma 2$ transcripts in that study is interesting, since we detected significant amounts of productive $\gamma 2$ transcripts in vivo. This difference could eventually reflect an absence of isotype-regulating signals in the in vitro conditions which could drive switching to the $\gamma 2$ isotype.

In one patient we found evidence that isotype-switching had occurred on both the productively and nonproductively rearranged allele. The ratio of productive and nonproductive transcripts was similar in all isotypes except $\alpha$, indicating that in most of the CLL cells the two Ig $\mathrm{H}$ chain loci had switched to the same $\mathrm{C}_{\mathrm{H}}$ genes. This finding is in agreement with investigations in human and mouse $\mathrm{B}$ cell lines which have shown that the VDJ genes in both chromosomes frequently switch to genes that encode the same $\mathrm{C}_{\mathrm{H}}$ isotype $(33,34)$.

We also provide evidence that the isotype-switched CLL transcripts can be translated and expressed as membrane Ig molecules. This was shown in the analysis of sorted surface $\mathrm{IgG}^{+}$cells that were selected from the PBL of two CLL patients. In both cases the CLL $\gamma$ transcripts were more abundant in the sorted than in the total PBL population, demonstrating that a subset of the CLL cells express surface IgG. However, it should be noted that the frequency of surface $\mathrm{IgG}^{+}$CLL cells was apparently very low because only a small percentage of the PBL in these two patients were positive by cytofluorimetric analysis and, as shown with the Ig gene finger- 


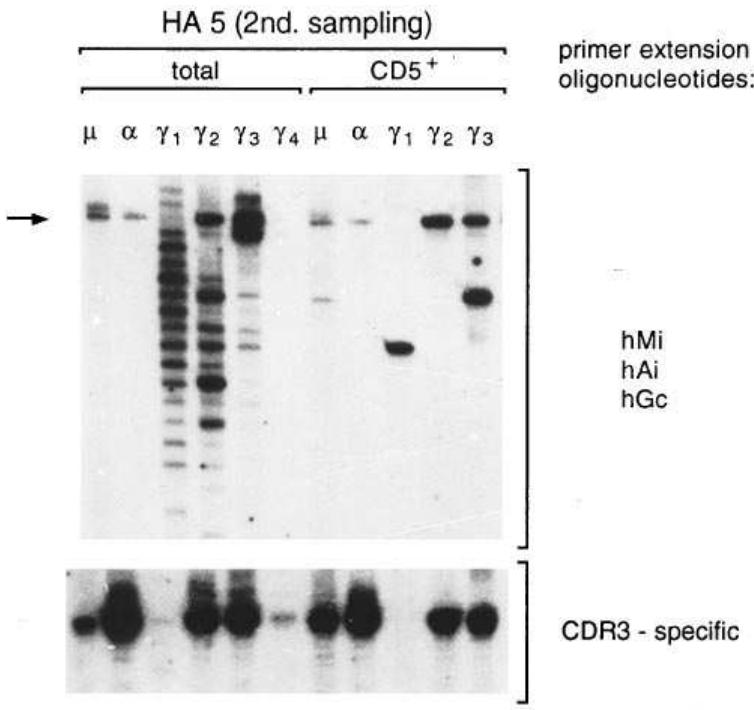

$\begin{array}{llllllllllll}\mu & \alpha & \gamma_{1} & \gamma_{2} & \gamma_{3} & \gamma_{4} & \mu & \alpha & \gamma_{1} & \gamma_{2} & \gamma_{3}\end{array}$ b

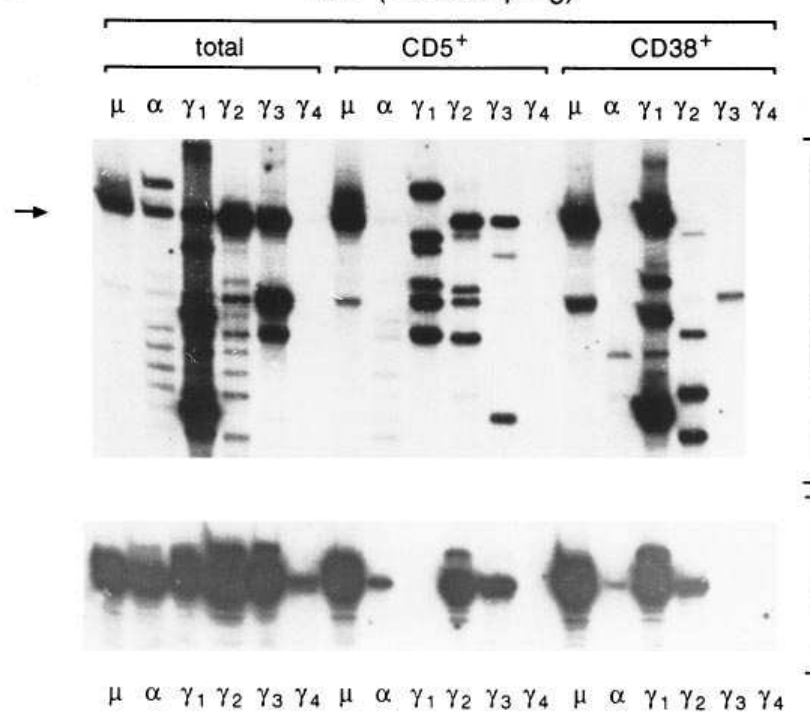

primer extension oligonucleotides:

CDR3 - specific
Figure 6. Detection of isotype-switched CLL transcripts in $\mathrm{CD}^{+} \mathrm{B}$ cells from patient HA5 $(a)$ and $\mathrm{CD}^{+}$and $\mathrm{CD} 38^{+} \mathrm{B}$ cells from patient CLP $(b)$. Analysis of total PBL samples was done in both cases for comparison. The primer extension reactions were done with internal $\mathrm{C}_{\mathrm{H}}$ primers (top) or CDR3-specific primers (bottom). Arrows indicate the bands that correspond to the CLL clones. printing, the isotype-switched CLL cells represented only a fraction of all surface $\mathrm{IgG}^{+} \mathrm{B}$ cells.

Ten of the CLL patients in our study had developed autoimmune hemolytic anemia (AIHA) during the course of their disease (cases HA1, HA2, HA4, HA5, HA6, HA7, HA8, HA11, HA-RI, and HA-Idr). The detection of isotype-switched CLL transcripts in all of these patients is especially intriguing with respect to the pathogenesis of this disorder. AIHA is frequent in CLL but rare in other B cell neoplasms, which implicates the transformed CLL lymphocyte in the development of this disease. On the other hand, the anti-erythrocyte autoantibodies in these patients are typically polyclonal $\mathrm{IgG}$, and therefore differ in $\mathrm{H}$ chain isotype from the $\mathrm{IgM}^{+} \mathrm{CLL}$ clone. We now show that these patients also contain CLL cells capable of producing secretory IgG antibodies which could be involved in the pathogenesis of the AIHA. In two of the CLLAIHA patients we also determined the type of secretory $\gamma$ transcripts that were produced by the CLL cells. Analysis of different samples collected during a two year period from the development of AIHA showed that the majority of secretory CLL $\gamma$ transcripts belong to the $\gamma 2$ and $\gamma 3$ subclasses. In one of the patients almost all of the secretory $\gamma 3$ transcripts were produced by the CLL clone. Antibodies of the IgG3 subclass seem to play an important role in the pathogenesis of the hemolytic anemia because of their high affinity for the FcyRIII which could promote the initial adherence of sensitized erythrocytes to macrophages (35). A role for the CLL Ig in the development of the hemolytic anemia is also supported by our recent finding of a restricted $\mathrm{H}$-chain variable region repertoire in CLL associated with AIHA, which is characterized by preferential expression of the $51 \mathrm{p} 1$ and DP-50 $\mathrm{V}_{\mathrm{H}}$ gene segments and $\mathrm{D}_{\mathrm{H}}$ genes from the DXP family (20). Studies are in progress to determine the specificity of these antibodies which should delineate the mechanisms through which the CLL Ig could promote the development of the hemolytic anemia.

To investigate if there are differences in the cell surface phenotypes of the isotype-switched CLL cells and their $\mathrm{IgM}^{+}$progenitors, we performed isotype-specific fingerprinting analysis 
of $\mathrm{CD}^{+}$and CD38 ${ }^{+}$PBL. The CD5 marker seems to be expressed by the majority but not all CLL cells, and could eventually be lost during B-cell differentiation $(36,37)$. The presence of isotype-switched CLL H-chain transcripts in the $\mathrm{CD}^{+}$ $\mathrm{B}$ cell population indicated that isotype-switching occurs in cells that still express the CD5 antigen. This analysis also showed that the majority of the $\alpha$ - and $\gamma$-expressing $\mathrm{CD}^{+} \mathrm{B}$ cells in the peripheral blood of the CLL patients are related to the malignant clone. Interestingly, the CLL $\gamma 1$ transcripts that were detected in the unfractionated PBL from one of the patients could not be detected among the transcripts produced by $\mathrm{CD}^{+} \mathrm{B}$ cells. However, CLL $\gamma 1$ transcripts were predominant among the $\gamma 1$ transcripts produced by $\mathrm{CD} 38^{+}$cells from this patient, indicating that some of the isotype-switched CLL cells might differentiate into $\mathrm{CD}^{-} / \mathrm{CD} 38^{+}$cells.

In most cases of CLL the leukemic cells express $V_{H}$ genes that contain little or no somatic mutations (for review see reference 38). However, some recent studies have reported mutations in CLL $\mathrm{V}_{\mathrm{H}}$ regions, particularly in association with the $\mathrm{V}_{\mathrm{H}} 251$ and $\mathrm{V}_{\mathrm{H}} 4.21$ genes $(39,40)$ and with CD5 negative CLL (41). Mutated $\mathrm{V}_{\mathrm{H}}$ genes have also been observed in isotypeswitched CLL variants, indicating that these two processes might be linked $(4,30,42)$. To investigate this possibility we performed nucleotide sequence analysis of $\alpha, \gamma 1, \gamma 2$, and $\gamma 3$ CLL H-chain transcripts from four cases that expressed $\mu$ VDJ transcripts in germ-line configuration. Three of these cases were chosen because the leukemic cells expressed strikingly similar $\mathrm{V}_{\mathrm{H}}$ regions that were encoded by the $51 \mathrm{p} 1$ gene in combination with a single reading frame of the DXP4 gene segment (20). This similarity in the antigen-binding sites indicated that these CLL clones have undergone antigen-driven stimulation and selection. The $\gamma 1$ transcripts expressed by CD $38^{+}$ CLL cells from case CLP were investigated because they were produced by potentially more differentiated cells and also contained the $V_{H} 4.21$ gene which is frequently found mutated in CLL. Sequence analysis of 48 different clones spanning the FW3-CH2 (or hinge) regions of the isotype-switched CLL transcripts showed that somatic mutations had not accumulated in the $\mathrm{V}_{\mathrm{H}}$ region sequences. The few mutations that were observed were equally distributed between the variable- and constant-regions and can therefore be regarded as Taq polymerase errors. The absence of mutations in the isotype-switched CLL transcripts suggests that the processes of class-switching and somatic mutation are distinct in the CLL lymphocyte. These data also indicate that the presence of somatic mutations in CLL might not reflect the stage of differentiation of the transformed cells, but rather the type of antigen stimulation or the capacity of the CLL cells to respond.

\section{Acknowledgments}

We are grateful to Dr. G. Presani for his help with the flow cytometry analysis, Drs. P. Tulissi and F. Franzin for collecting some of the samples, and Drs. A. Bradbury and S. Anand for critical reading of the manuscript.

\section{References}

1. Foon, K.A., K.R. Rai, and R.P. Gale. 1990. Chronic lymphocytic leukemia: new insights into biology and therapy. Ann. Int. Med. 113:525-539.

2. Dighiero, G., P. Travade, S. Chevret, P. Fenaux, C. Chastang, J.-L. Binet, and the French Cooperative Group on CLL. 1991. B-cell chronic lymphocytic leukemia: Present status and future directions. Blood 78:1901-1914.
3. Geisler, C.H., J.K. Larsen, N.E. Hansen, M.M. Hansen, B.E. Christensen, B. Lund, H. Nielsen, T. Plesner, K. Thorling, E. Andersen, and P.K. Andersen. 1991. Prognostic importance of flow cytometric immunophenotyping of 540 consecutive patients with B-cell chronic lymphocytic leukemia. Blood. 78:1795-1802.

4. Friedman, D.F., J.S. Moore, J. Erikson, J. Manz, J. Goldman, P.C. Nowell, and L.E. Silberstein. 1992. Variable region gene analysis of an isotypeswitched (IgA) variant of chronic lymphocytic leukemia. Blood. 80:2287-2297.

5. Fu, S.M., N. Chiorazzi, H.G. Kunkel, J.P. Halper, and S. Harris. 1978. Induction of in vitro differentiation and immunoglobulin synthesis of human leukemic B lymphocytes. J. Exp. Med. 148:1570-1578.

6. Totterman, T.H., N. Nilsson, and C. Sundstrom. 1980. Phorbol esterinduced differentiation of chronic lymphocytic leukemia cells. Nature (Lond.). 288:176-178.

7. Gordon, J., H. Mellstedt, P. Aman, P. Biberfeld, and G. Klein. 1984. Phenotypic modulation of chronic lymphocytic leukemia cells by phorbol ester: Induction of IgM secretion and changes in the expression of B cell-associated surface antigens. J. Immunol. 132:541-547.

8. Juliusson, G., K.-H. Rober, L. Hammarstrom, C.I.E. Smith, G. Biberfeld, and G. Gahrton. 1983. Mitogen-induced switching of immunoglobulin heavychain class secretion in chronic B-lymphocytic leukaemia and immunocytoma cell populations. Scand. J. Immunol. 17:51-59.

9. Sarfati, M., H. Luo, and G. Delespesse. 1989. IgE synthesis by chronic lymphocytic leukemia cells. J. Exp. Med. 170:1775-1780.

10. Fu, S.M., R.J. Winchester, T. Feizi, P.D. Walzer, and H.G. Kunkel. 1974. Idiotypic specificity of surface immunoglobulin and the maturation of leukemic bone-marrow-derived lymphocytes. Proc. Natl. Acad. Sci. USA. 71:44874490.

11. Deegan, M.J., J.P. Abraham, M. Sawdyl, and E.J. van Slyck. 1984. High incidence of monoclonal proteins in the serum and urine of chronic lymphocytic leukemia patients. Blood. 64:1207-1211.

12. Sinclair, D., J.H. Dagg, A.E. Dewar, A.M. Mowat, D.M.V. Parrot, G. Stockdill, and D.I. Stott. 1986. The incidence, clonal origin and secretory nature of serum paraproteins in chronic lymphocytic leukemia. Br. J. Haematol. 64: 725-735.

13. Pezzoli, A., and E. Pascali. 1986. Monoclonal Bence Jones proteinuria in chronic lymphocytic leukemia. Scand J. Haematol. 36:18-24.

14. Qian, G.-X., S.M. Fu, D.L. Solanki, and K.R. Rai. 1984. Circulating monoclonal IgM proteins in B cell chronic lymphocytic leukemia: Their identification, characterization and relationship to membrane IgM. J. Immunol. 133: 3396-3400.

15. Hansen, D.A., B.A. Robbins, D.J. Bylund, L.D. Piro, A. Saven, and D.J. Ellison. 1994. Identification of monoclonal immunoglobulins and quantitative immunoglobulin abnormalities in hairy cell leukemia and chronic lymphocytic leukemia. Am. J. Clin. Pathol. 102:580-585.

16. Beaume, A., A. Bizard, B. Dreyfus, and J.-L. Preud'homme. 1994. High incidence of serum monoclonal Igs detected by a sensitive immunoblotting technique in B-cell chronic lymphocytic leukemia. Blood. 84:1216-1219.

17. Chomczynski, P., and N. Sacchi. 1987. Single-step method of RNA isolation by acid guanidinium thiocyanate-phenol-chloroform extraction. Anal. Biochem. 162:156-159.

18. Kabat, E.A., T.T. Wu, H.M. Perry, K.S. Gottesman, and C. Foeller. 1991. Sequences of proteins of immunological interest (ed. 5). US Department of Health and Human Services, Bethesda, MD.

19. Efremov, D.G., F.D. Batista, and O.R. Burrone. 1993. Molecular analysis of IgE H-chain transcripts expressed in vivo by peripheral blood lymphocytes from normal and atopic individuals. J. Immunol. 151:2195-2207.

20. Efremov, D.G., M. Ivanovski, N. Siljanovski, G. Pozzato, L. Cevreska, F. Fais, N. Chiorazzi, F.D. Batista, and O.R. Burrone. 1996. Restricted immunoglobulin $\mathrm{V}_{\mathrm{H}}$ region repertoire in chronic lymphocytic leukemia patients with autoimmune hemolytic anemia. Blood. 87:3869-3876.

21. Tomlinson, I.M., G. Walter, J.D. Marks, M.B. Llewelyn, and G. Winter. 1992. The repertoire of human germline $V_{H}$ sequences reveals about fifty groups of $\mathrm{V}_{\mathrm{H}}$ segments with different hypervariable loops. J. Mol Biol. 227:776798.

22. Deane, M., and J.D. Norton. 1990. Detection of immunoglobulin gene rearrangement in B lymphoid malignancies by polymerase chain reaction gene amplification. Br. J. Haematol. 74:251-256.

23. Franzin, F., D.G. Efremov, G. Pozzato, P. Tulissi, F. Batista, and O.R Burrone. 1995. Clonal B-cell expansions in peripheral blood of HCV-infected patients. Br. J. Haematol. 90:548-552.

24. Baumann, B., M.J. Potash, and G. Kohler. 1985. Consequences of frameshift mutations at the immunoglobulin heavy chain locus of the mouse. EMBO J. 4:351-359.

25. Lozano, F., B. Maertzdorf, R. Pannell, and C. Milstein. 1994. Low cytoplasmatic mRNA levels of immunoglobulin $\kappa$ light chain genes containing nonsense codons correlate with inefficient splicing. EMBO J. 13:4617-4622.

26. Bhan, A.K., L.M. Nadler, P. Stashenko, R.T. McCluskey, and S.F. Schlossman. 1981. Stage of B cell differentiation in human lymphoid tissue. $J$. Exp. Med. 154:737-749.

27. Jackson, D.G., and J.I. Bell. 1990. Isolation of a cDNA encoding the human CD38(T10) molecule cell surface glycoprotein with an unusual discontinu- 
ous pattern of expression during lymphocyte differentiation. J. Immunol. 144: 2811-2815.

28. Newman, R.A., B. Peterson, F.R. Davey, C. Brabyn, H. Collins, V.L. Brunetto, D.B. Duggan, R.B. Weiss, I. Royston, F.E. Millard, A.A. Miller, and C.D. Bloomfield. 1993. Phenotypic markers and BCL-1 gene rearrangements in B-cell chronic lymphocytic leukemia: a cancer and leukemia group B study. Blood. 82:1239-1246.

29. Jacob, J., G. Kelsoe, K. Rajewsky, and U. Weiss. 1991. Intraclonal generation of antibody mutants in germinal centres. Nature (Lond.). 354:389-392.

30. Ebeling, S.B., M.E.M. Schutte, and T. Logtenberg. 1993. Molecular analysis of $\mathrm{V}_{\mathrm{H}}$ and $\mathrm{V}_{\mathrm{L}}$ regions expressed in IgG-bearing chronic lymphocytic leukemia (CLL): Further evidence that CLL is a heterogenous group of tumors. Blood. 82:1626-1631.

31. Wakai, M., S. Hashimoto, M. Omata, Z.M. Sthoeger, S.L. Allen, S.M. Lichtman, P. Schulman, V.P. Vinciguerra, B. Diamond, M. Dono, M. Ferrarini, and N. Chiorazzi. 1994. IgG+, CD5+ human chronic lymphocytic leukemia B cells. Production of IgG antibodies that exhibit diminished autoreactivity and IgG subclass skewing. Autoimmunity. 19:39-48.

32. Sideras, P., L. Nilsson, K.B. Islam, I.Z. Quintana, L. Friehof, A. Rosen, G. Juliusson, L. Hammarstrom, and C.I.E. Smith. 1992. Transcription of unrearranged Ig H chain genes in human B cell malignancies: Biased expression of genes encoded within the first duplication unit of the Ig H chain locus. J. Immunol. 149:244-252.

33. DePinho, R., K. Kruger, N. Andrews, S. Lutzker, D. Baltimore, and F.W. Alt. 1984. Molecular basis of heavy-chain class switching and switch region deletion in an Abelson virus-transformed cell line. Mol. Cell. Biol. 4:29052910.
34. Radbruch, A., W. Muller, and K. Rajewsky. 1986. Class switch recombination is IgG1 specific on active and inactive IgH loci of IgG1-secreting B-cell blasts. Proc. Natl. Acad. Sci. USA. 83:3954-3957.

35. Engelfriet, C.P., M.A.M. Overbeeke, and A.E.G.K. von dem Borne. 1992. Autoimmune hemolytic anemia. Sem. Hematol. 29:3-12.

36. Faguet, G.B., and J.F. Agee. 1992. CD5 and cCLLa expression in chronic lymphocytic leukemia (CLL): Demonstration of their relative prevalence and that of other common B-CLL markers. Leuk. Lymphoma. 6:335-344.

37. Hardy, R.R., and K. Hayakawa. 1993. CD5 B cells, a fetal B cell lineage. Adv. Immunol. 55:297-339.

38. Kipps, T.J., and D.A. Carson. 1993. Autoantibodies in chronic lymphocytic leukemia and related systemic autoimmune diseases. Blood. 81:2475-2487.

39. Cai, J., C. Humphries, A. Richardson, and P.W. Tucker. 1992. Extensive and selective mutation of a rearranged $\mathrm{V}_{\mathrm{H}} 5$ gene in human $\mathrm{B}$ cell chronic lymphocytic leukemia. J. Exp. Med. 176:1073-1081.

40. Schroeder, H.W. Jr., and G. Dighiero. 1994. The pathogenesis of chronic lymphocytic leukemia: analysis of the antibody repertoire. Immunol. Today. 15:288-294.

41. Roudier, J., G.J. Silverman, P.P. Chen, D.A. Carson, and T.J. Kipps. 1990. Intraclonal diversity in the $\mathrm{V}_{\mathrm{H}}$ genes expressed by CD5-negative chronic lymphocytic leukemia producing pathogenic IgM rheumatoid factor. J. Immunol. $144: 1526-1529$

42. Hashimoto, S., M. Dono, M. Wakai, S.L. Allen, S.M. Lichtman, P. Schulman, V.P. Vinciguerra, M. Ferrarini, J. Silver, and N. Chiorazzi. 1995. Somatic diversification and selection of immunoglobulin heavy and light chain variable region genes in $\mathrm{IgG}^{+} \mathrm{CD}^{+}$chronic lymphocytic leukemia B cells. $J$. Exp. Med. 181:1507-1517. 